\title{
Poor Eating Habits and Predictors of Weight Gain During the COVID-19 Quarantine Measures in Kuwait: A Cross Sectional Study
}

Nouf S ALMughamis ( $\nabla$ almughamisn@gmail.com )

https://orcid.org/0000-0002-5285-6543

Shaimaa AlAsfour

Ministry of Health Kuwait

Shariq Mehmood

Lahore Medical and Dental College

\section{Research note}

Keywords: weight gain, COVID-19, quarantine, binge-eating, anxiety

Posted Date: May 27th, 2020

DOI: https://doi.org/10.21203/rs.3.rs-29219/v1

License: (c) (i) This work is licensed under a Creative Commons Attribution 4.0 International License.

Read Full License

Version of Record: A version of this preprint was published at F1000Research on August 5th, 2020. See the published version at https://doi.org/10.12688/f1000research.25303.1. 


\section{Abstract}

Objective Despite the public health importance of documenting the burden of physical inactivity and weight gain, there is a paucity of such data in Kuwait during the lockdown for Covid-19 pandemic. Therefore, this survey was designed to estimate: the burden of poor eating habits particularly binge eating habits, fluctuations in weight and its predictors among the Kuwaiti public.

Results There was a total of 522 valid respondents, with a mean age of 41.78 (11.75) years. There was a significant increase in weight of respondents during the quarantine (mean difference $=-1.13$, SD $5.39, t=$ $-4.52, p<0.001)$. Those with reporting unhealthy diets were 4.5 times more likely to report an increase in weight. Those reporting having anxiety throughout the day were 2.45 times more likely and those consuming snacks excessively were associated with 3.27 times higher odds of increase in weight than those not consuming it.

\section{Introduction}

These are unusual times, as pandemic of COVID-19 has drastically affected daily lives of millions of people around the world. The concept of quarantine is practically new for the general public, which has influenced social, economic and psychological threads of our life [1, 2]. Particularly due to changes in our habits including socializing, physical work, eating and entertainment, it is but natural that level of anxiety and depression is on rise among people in quarantine [3]. The psychological impact of quarantine has also been associated with post-traumatic stress, confusion and aggression [1].

Among the general masses, poor information pertaining to the COVID-19 and the rationale for lockdown has given birth to fear toward infection, frustration, boredom, financial loss and stigma [1]. These stressors may lead to people being homebound and lead a sedentary lifestyle and develop poor eating habits. This poor lifestyle can be detrimental to the health structure of middle eastern countries especially Kuwait, where obesity has a high prevalence among people of Gulf countries, where a huge proportion of Kuwaiti national meet the World Health Organization's definition of 'obesity' [4]. According to Al-Nohair, the prevalence of obesity among Kuwaiti males is $36 \%$ and females is $48 \%[4,5]$. This high rate of obesity in Kuwait has been attributed to a plethora of biopsychosocial risk factors and a polygenic etiology [4]. And current situation of pandemic and associated quarantine may further exacerbate the situation [1].

Due to a disrupted daily routine of adults and children, less social contact and rising psychological distress, the health of Kuwaiti residents can further deteriorate both physically and mentally [1]. All of these factors have been documented to particularly affect healthy eating habits [6]. Over-eating and resulting weight gain during the COVID-19 quarantine, may result in an increase in incidence of chronic diseases such as diabetes, cardiovascular diseases and psychiatric illnesses. And epidemiological and public health studies focusing on nutrition and weight gain among the general masses are a need of the hour to develop strategies and devise interventions countering these. 
Despite the public health importance of documenting the burden of physical inactivity and weight gain, there is a paucity of such data in Kuwait. Therefore, this survey was designed to estimate: the burden of poor eating habits particularly binge eating habits, fluctuations in weight and its predictors among the Kuwaiti public.

\section{Methods}

This cross-sectional survey was conducted from 2nd to 12th April 2020 among the general public in Kuwait. All data were collected through social media platform (WhatsApp groups), through convenience and snowball sampling methods. Inclusion criteria included participants being Kuwaiti nationals residing in Kuwait. There were no specific exclusion criteria pertaining to age, language, gender or occupation of the respondents. After signing a written informed consent, the respondents were briefed about the objectives of the survey, ensured anonymity and that the group findings will be reported. Respondents could leave the study at any time if they felt uncomfortable. Approval for this study was provided by the Ethical Review Board of Ministry of Health of Kuwait, Kuwait.

Minimum sample size required for this survey was calculated to answer out primary research objective of documenting prevalence of poor eating habits among Kuwaitis. Based on a statistical power of $80 \%$, confidence level $95 \%$, margin of error $5 \%$ and a population size of 1.3 million Kuwaitis, a minimum sample size of 385 was required. All data were collected using an electronic version of a bilingual questionnaire in Arabic and English language. Participants were encouraged to provide their responses in either of the languages. The questionnaire comprised of three sections: a) demographic characteristics of respondents, $b$ ) eating habits particularly binge eating, consumption of snacks and beverages $c$ ) subjective feelings of anxiety and d) weight before and during the pandemic. Demographic characteristics included gender, age, nationality, marital status, parity and housing of the respondents. Several questions were asked regarding binge eating habits documenting change in nutrition habits, time of increased food consumption, number and type of snack foods consumed during the day, water and coffee intake. Physical activity during the day was inquired using two questions: a) a trichotomous question documenting change in physical activity when compared with normal routine before the quarantine and number of hours spent in a sedentary manner per day in the last week. Symptoms of anxiety were measured subjectively using a three point Likert type question. Participants were asked the extent to which they experienced anxiety every day in last 7 days. Responses were given on a three point scale ranging from never to always.

All data were analyzed using the SPSS (v.25). Descriptive statistics were calculated for all variables where quantitative variables were presented as mean (SD) and categorical ones as frequency and percentage. Statistical significance for difference between weight of respondents during the COVID-19 pandemic and before it was assessed using t-test for dependent samples. To delineate predictors of weight gain, it was planned apriori to run multiple regression however due to non-normal nature of the data, preference was given to logistic regression analysis. 
Thereafter, the respondents were categorized in to two groups: participants with weight gain and participants with negative or no change in weight. To identify the predictors of experience in weight gain among the Kuwaitis, binary logistic regression (stepwise method) was employed. Theoretically sound factors showing relationship with weight gain in previous literature were added as predictors in the logistic regression model. These predictors included demographic characteristics of respondents, eating habits $\mathrm{c}$ ) subjective feelings of anxiety and d) questions pertaining to physical inactivity. The final model reported significant predictors of weight, with statistical significance set at $\leq 0.05$.

\section{Results}

\section{Characteristics of respondents}

There were a total of 522 valid respondents, with a mean age of 41.78 (11.75) years. A majority of the respondents were females $(380,72.8 \%)$ than males $(142,27.2 \%)$. A higher proportion of the respondents were married $(379,72.6 \%)$ than single $(97,18.6 \%)$. A total of $201(38.5 \%)$ respondents reported having $1-$ 3 children, followed by $3-6(170,32.6 \%)$, no children (124, 23.8\%) and more than 6 children 27 (5.2\%). More than half of the respondents lived in their own houses 297 (56.9\%), followed by at parents' house 128 (24.5\%), and apartment 97 (18.6\%).

\section{Weight and eating patterns before the COVID-19 pandemic}

A higher proportion of the respondents' families were assisted by a cook $(299,57.3 \%)$ to prepare meals than themselves $(223,42.7 \%)$. A change in nutritional habits was reported by $387(74.1 \%)$ respondents with 214 reporting that their eating pattern had improved to a healthier one $(214,41 \%)$ than unhealthy one $(24.3 \%)$. Respondents tend to consume more food at night $(232,44.4 \%)$ than during daytime. A total of 352 respondents $(67.4 \%)$ reported consuming snacks more than 2 times per day. Water intake was reported as enough $(287,55.0 \%)$ and 300 (57.5\%) respondents reported having $1-3$ cups of coffee a day.

The question regarding weight of the respondents before and during the lockdown, there were 462 $(88.50 \%)$ valid responses. No imputation for missing responses was conducted at this stage due to extent of missing responses. Mean weight of respondents before the pandemic was $75.03(16.85) \mathrm{kg}$ and 75.74 (17.54) kg during the pandemic (Fig. 1). There was a significant increase in weight of respondents during the quarantine (mean difference $=-1.13, \operatorname{SD} 5.39, \mathrm{t}=-4.52, \mathrm{p}<0.001$ ). A higher proportion of respondents reported that their weight will stabilize after the pandemic while 217 (41.6\%) reported that it would increase. A total of $333(63.8 \%)$ of the respondents reported feeling anxious sometimes during the day, $133(25.5 \%)$ always and $56(10.7 \%)$ never. Over $69 \%$ of the respondents reported that their physical activity had reduced than before. Mean number of hours spent being sedentary at home were 9.56 (5.64) (Table 1). 
Table 1

Eating habits during COVID-19

\begin{tabular}{|c|c|c|c|}
\hline Statement & Response & Frequency & Percentage \\
\hline \multirow[t]{2}{*}{ Who cooks at home? } & Cook & 298 & $57.2 \%$ \\
\hline & Self or family member & 223 & $42.8 \%$ \\
\hline \multirow{3}{*}{$\begin{array}{l}\text { Have you changed your nutritional habits at } \\
\text { home? }\end{array}$} & No & 135 & $25.9 \%$ \\
\hline & To an extent & 174 & $33.3 \%$ \\
\hline & Yes & 213 & $40.8 \%$ \\
\hline \multirow[t]{3}{*}{ how has your eating habit changed? } & Became unhealthy & 127 & $24.3 \%$ \\
\hline & No change & 181 & $34.7 \%$ \\
\hline & Became healthier & 214 & $41.0 \%$ \\
\hline \multirow[t]{4}{*}{ When do you tend to consume more food? } & Eat more at day & 82 & $15.8 \%$ \\
\hline & Eat more at night & 232 & $44.6 \%$ \\
\hline & $\begin{array}{l}\text { Eat more at night and } \\
\text { day }\end{array}$ & 12 & $2.3 \%$ \\
\hline & No change & 194 & $37.3 \%$ \\
\hline \multirow[t]{7}{*}{ Main meals during COVID-19 } & Breakfast & 28 & $5.36 \%$ \\
\hline & Breakfast \& Dinner & 43 & $8.24 \%$ \\
\hline & Breakfast \& Lunch & 50 & $9.58 \%$ \\
\hline & $\begin{array}{l}\text { Breakfast, Lunch and } \\
\text { Dinner }\end{array}$ & 153 & $29.31 \%$ \\
\hline & Dinner & 47 & $9.0 \%$ \\
\hline & Lunch & 95 & $18.20 \%$ \\
\hline & Lunch \& Dinner & 106 & $20.31 \%$ \\
\hline \multirow[t]{5}{*}{ Snack during COVID } & None & 38 & $7.3 \%$ \\
\hline & Once a day & 132 & $25.3 \%$ \\
\hline & Twice a day & 166 & $31.8 \%$ \\
\hline & Thrice a day & 89 & $17.0 \%$ \\
\hline & More than 3 times a day & 97 & $18.6 \%$ \\
\hline \multirow[t]{2}{*}{ Water intake during COVID-19 } & Not enough & 233 & $44.8 \%$ \\
\hline & Enough & 287 & $55.2 \%$ \\
\hline
\end{tabular}




\begin{tabular}{|c|c|c|c|}
\hline Statement & Response & Frequency & Percentage \\
\hline \multirow[t]{3}{*}{ Coffee during COVID-19 } & No coffee & 141 & $27.1 \%$ \\
\hline & $1-3$ cups & 300 & $57.6 \%$ \\
\hline & $>3$ cups & 80 & $15.4 \%$ \\
\hline \multirow[t]{3}{*}{ Physical activity } & As it was & 85 & $16.3 \%$ \\
\hline & Less & 363 & $69.5 \%$ \\
\hline & More & 74 & $14.2 \%$ \\
\hline \multirow[t]{3}{*}{ What will happen to weight after covid-19 } & Decrease & 0 & $0.0 \%$ \\
\hline & Stabilise & 304 & $58.3 \%$ \\
\hline & Increase & 217 & $41.7 \%$ \\
\hline \multirow[t]{3}{*}{ I feel anxious } & Never & 56 & $10.7 \%$ \\
\hline & Sometimes & 333 & $63.8 \%$ \\
\hline & Always & 133 & $25.5 \%$ \\
\hline
\end{tabular}

\section{Predictors of weight increase among the Kuwaitis}

Logistic regression (stepwise method) was run to analyze statistically significant predictors of increase in weight among the Kuwaitis during the COVID-19 quarantine. It yielded a significant model $\left(X^{2}=90.43\right.$, df $=8, p<0.001$ ). The model explained $24.9 \%$ of variance in weight changes among Kuwaitis (Nagelkerke $\mathrm{R}^{2}$ ) and correctly classified $71.6 \%$ of the cases, whereas sensitivity of this particular model was $65.8 \%$ and specificity $78 \%$ in predicting the increase in weight among Kuwaiti respondents. According to this model, when compared with respondents who changed their diet pattern to healthier, those with reporting unhealthy diets were 4.5 times $(95 \% \mathrm{Cl}=2.45$ to 8.23$)$ more likely to report an increase in weight. Those reporting having anxiety throughout the day were 2.45 times more likely to have an increase in weight than those never experiencing it. Consuming snacks excessively ( $>3$ times a day) was associated with 3.27 times higher odds of increase in weight than those not consuming it. Consuming moderate amounts of snacks $(1-3)$ times a day did not differ than their counterparts who never consumed snacks throughout the day (Table 2). 
Table 2

Predictors of increased weight among Kuwaitis $(n=462)$

\begin{tabular}{|c|c|c|c|c|c|c|}
\hline \multirow[t]{2}{*}{ Variable } & \multirow[t]{2}{*}{ B } & \multirow[t]{2}{*}{ S.E. } & \multirow[t]{2}{*}{$\mathbf{P}$} & \multirow{2}{*}{$\begin{array}{l}\text { Odds ratio } \\
\text { (OR) }\end{array}$} & \multicolumn{2}{|c|}{ 95\% C.I. for OR } \\
\hline & & & & & Lower & Upper \\
\hline $\begin{array}{l}\text { how has your eating habit } \\
\text { changed? }\end{array}$ & & & $\begin{array}{l}< \\
0.001\end{array}$ & & & \\
\hline \multicolumn{7}{|l|}{ Became healthy } \\
\hline Became unhealthier & 1.505 & 0.311 & $<001$ & 4.506 & 2.448 & 8.295 \\
\hline No change & 0.057 & 0.235 & .809 & 1.058 & 0.668 & 1.677 \\
\hline Snack during COVID & & & $\begin{array}{l}< \\
0.001\end{array}$ & & & \\
\hline \multicolumn{7}{|l|}{ None } \\
\hline Once a day & -0.403 & 0.445 & 0.365 & 0.668 & 0.279 & 1.600 \\
\hline Twice a day & -0.276 & 0.434 & 0.525 & 0.759 & 0.324 & 1.778 \\
\hline Thrice a day & 0.369 & 0.477 & 0.440 & 1.446 & 0.568 & 3.681 \\
\hline More than 3 times a day & 1.186 & 0.494 & 0.016 & 3.273 & 1.244 & 8.613 \\
\hline I feel anxious & & & 0.085 & & & \\
\hline \multicolumn{7}{|l|}{ Never } \\
\hline Sometimes & 0.626 & 0.361 & 0.083 & 1.870 & 0.921 & 3.796 \\
\hline Always & 0.896 & 0.404 & 0.026 & 2.451 & 1.110 & 5.410 \\
\hline Constant & -0.945 & 0.501 & 0.059 & 0.389 & & \\
\hline
\end{tabular}

\section{Discussion}

The present study documents change in dietary patterns among Kuwait residents during this COVID-19 pandemic. According to our results, a high proportion of Kuwaitis reported binge eating habits and a sedentary lifestyle and an increase in their weight during the quarantine. Significant predictors of weight gain among the Kuwaitis included unhealthy diet pattern, excessive consumption of snacks and subjective feelings of anxiety.

Our study reports a high prevalence of unhealthy eating habits and sedentary lifestyle during the pandemic, which contributed to a significant weight increase among the Kuwaitis. Albeit in the past, several studies have reported high rates of unhealthy habits and obesity among the Kuwaiti public, this situation may have worsened during the lockdown. This time of pandemic and quarantine has affected 
almost all aspects of life and the pattern of unhealthy eating habits have become more prevalent including excessive consumption of snacks, predicting an increase in weight of the studied population. Our study also showed that a higher proportion of respondents assume that their eating pattern has become healthier but at the same time the frequency of snacks binge eating, and night-time consumption of food showed statistical significance, leading to unhealthy patterns of food consumption. An increase in weight gain and development of unhealthy eating habits will present as a challenge post-COVID era, and policies must be devised to strengthen health systems to tackle this.

Another important predictor of weight included subjective feelings of anxiety during this era, which not only carry negative physical and mental health implication but also contribute to 'stress-eating' and 'food cravings'[7-12]. Feeling anxious during this era of pandemic is natural and eating more carbohydrates and binge eating likely improve mood for some time but leads to gain of weight and chronic diseases incidence also contribute to poorer body image [7-12]. This double burden of poor mental health and obesity thus, presents as a great challenge to the public health professionals and interventions must be devised to ensure good mental health during these trying times. Several interventions especially psychoeducation related to this pandemic and meditation interventions can be televised to ease off worry and stress and reduce anxiety levels among the general public.

The results from this study can serve as a guiding tool for shaping health strategy during this pandemic by health authorities. As Gulf countries grew enormously in wealth, living standards were raised, albeit at a cost of more sedentary and comfortable life routine $[5,13,14]$. Kuwait had previously developed a 'Kuwait National Programme for Healthy Living (2013-2017)'[15], authorities can develop a strategic plan to counter harmful effects of this pandemic on health that are originating from sedentary lifestyle, unhealthy eating patterns and psychological issues.

\section{Limitations}

Despite its large sample size, this study has several limitations which need to be considered for careful interpretation of its results. Most important limitations include a convenience and snowballing approach for collection of data as opposed to random sampling. Cross-sectional nature of this study limits inferences related to causality and temporality and use of a subjective question for estimating anxiety levels limit validity of these results and also introduce recall bias. Future studies should consider a prospective study design and use of valid and reliable questionnaires like the Generalized Anxiety Disorder 7-item scale [16].

\section{Abbreviations}

Not applicable

\section{Declarations}




\section{Ethics approval and consent to participate}

Approval for this study was provided by the Ethical Review Board of Ministry of Health of Kuwait, Kuwait. Written informed consent was taken from all participating mothers, who were ensured anonymity and that only group findings would be reported.

\section{Consent for publication}

Not applicable.

\section{Availability of data and material}

All data associated with this manuscript are available on request to the corresponding author.

\section{Competing interests}

The authors report no declarations of interest.

\section{Funding}

There was no funding for this study.

\section{Authors' contributions (NAM, SAA, SM)}

NAM conceived the study and SM performed statistical analysis. NAM \& SM drafted the manuscript. NAM, SAA participated in the study design, and data collection and revised it critically. All authors read and approved the final manuscript.

\section{Acknowledgements}

The authors thank Dr. Ahmed Waqas, doctoral fellow at the University of Liverpool, Liverpool, UK, for providing assistance in data analysis.

\section{References}

1. Brooks SK, Webster RK, Smith LE, Woodland L, Wessely S, Greenberg N, et al. The psychological impact of quarantine and how to reduce it: rapid review of the evidence. Lancet. 2020;395:912-20. doi:10.1016/S0140-6736(20)30460-8. 
2. Kaplan J, Frias L, McFall-Johnsen M. A third of the global population is on coronavirus lockdown here's our constantly updated list of countries locking down and opening up. 2020. https://www.businessinsider.com.au/countries-on-lockdown-coronavirus-italy-2020-3.

3. Zohn Rosen, Sarah L. Weinberger-Litman, Cheskie Rosenzweig, David H. Rosmarin, Peter Muennig, Ellie R Carmody, Sukumar T. Rao LL. Anxiety and distress among the first community quarantined in the U.S due to COVID-19: Psychological implications for the unfolding crisis. J Chem Inf Model. 2020;53:1689-99.

4. Alnohair S. Obesity in Gulf Countries. Int J Health Sci (Qassim). 2014;8:79-83.

5. Badr HE. Differences in physical activity , eating habits and risk of obesity among Kuwaiti adolescent boys and girls: a population-based study. International journal of adolescent medicine and health. 2017;:1-9.

6. Muscogiuri G, Barrea L, Savastano S, Colao A. Nutritional recommendations for CoVID-19 quarantine. Eur J Clin Nutr. 2020;:10-1.

7. Vidovi V, Henigsberg N, Jure V. Anxiety and Defense Styles in Eating Disorders. Collegium antropologicum. 2003;1:125-34.

8. Aoun C, Nassar L, Soumi S, El Osta N, Papazian T, Rabbaa Khabbaz L. The Cognitive, Behavioral, and Emotional Aspects of Eating Habits and Association With Impulsivity, Chronotype, Anxiety, and Depression: A Cross-Sectional Study. Front Behav Neurosci. 2019.

9. Higgins DM, Dorflinger L, MacGregor KL, Heapy AA, Goulet JL, Ruser C. Binge eating behavior among a national sample of overweight and obese veterans. Obesity. 2013.

10. Verplanken B. Beyond frequency: Habit as mental construct. Br J Soc Psychol. 2006 ;45(3):639-56.

11. Yannakoulia M, Panagiotakos DB, Pitsavos C, Tsetsekou E, Fappa E, Papageorgiou C, et al. Eating habits in relations to anxiety symptoms among apparently healthy adults. A pattern analysis from the ATTICA Study. Appetite. 2008;51(3):519-25.

12. Schulz S, Laessle RG. Associations of negative affect and eating behaviour in obese women with and without binge eating disorder. Eat Weight Disord. 2010 ;15(4):e287-93.

13. Musaiger AO. Consumption, Health Attitudes and Perception Toward Fast Food Among Arab Consumers in Kuwait: Gender Differences. Global Journal of Health Science. 2014;6:136-43.

14. Balhareth A, Meertens R, Kremers S, Sleddens E. Overweight and obesity among adults in the Gulf States: A systematic literature review of correlates of weight, weight-related behaviours, and interventions. Obes Rev. 2019;20:763-93.

15. Behbehani K. Kuwait National Programme for Healthy Living: First 5-Year Plan ( 2013 - 2017). 2017;23 suppl 1:32-42.

16. Spitzer RL, Kroenke K, Williams JBW, Löwe B. A brief measure for assessing generalized anxiety disorder: The GAD-7. Arch Intern Med. 2006.

\section{Figures}




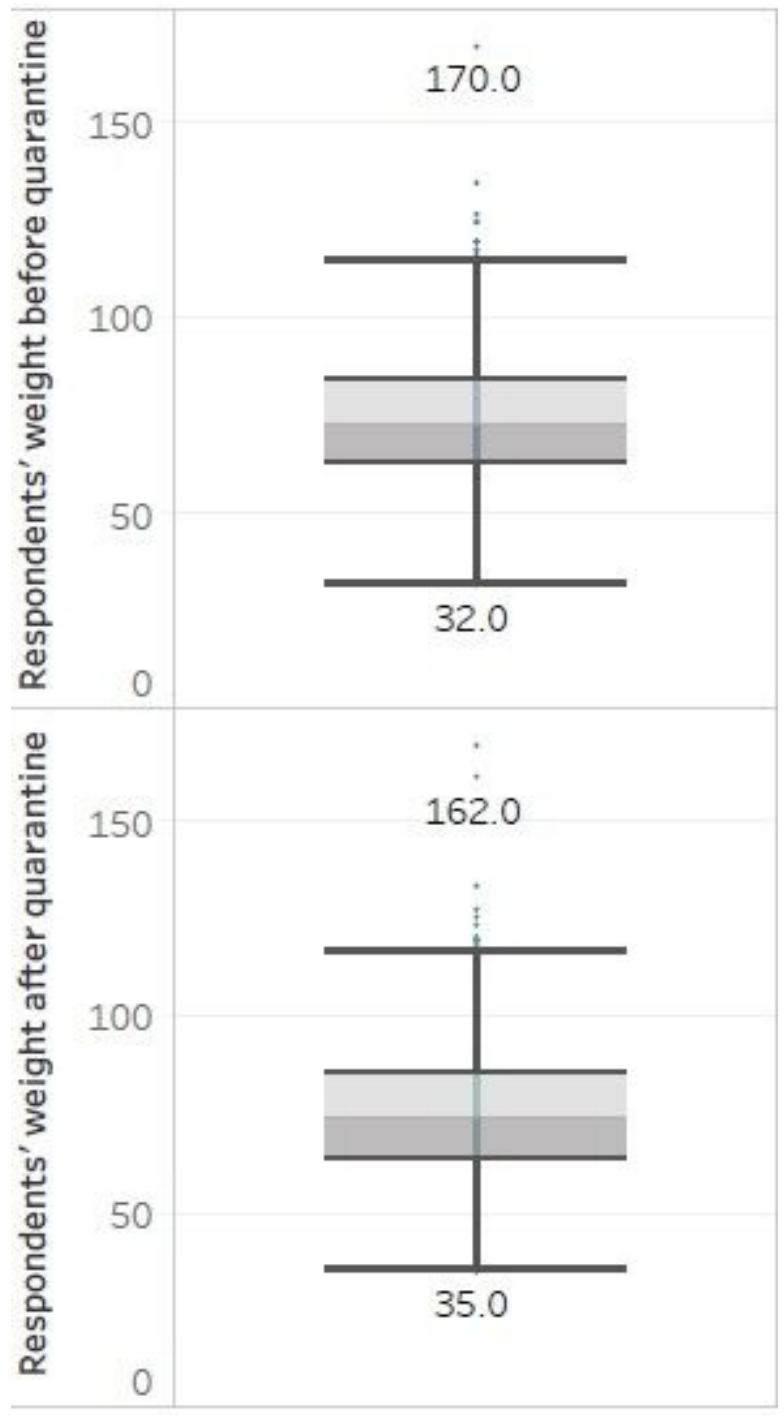

Figure 1

Distribution of weight of respondents before and after COVID-19 quarantine

\section{Supplementary Files}

This is a list of supplementary files associated with this preprint. Click to download.

- CovidKuwaitWtSurvey.pdf 